\title{
The National Health Insurance Scheme in Ghana: Prospects and Challenges: a Cross-Sectional Evidence
}

\author{
Freeman F. K. Gobah (Corresponding Author) \\ School of Medicine and Health Management, Tongji Medical College \\ Huazhong University of Science and Technology, 13 Hang Kong Road, Wuhan, China \\ Tel: 86-136-9735-0839_E-mail: fgobah@yahoo.co.uk, feddy25@gmail.com
}

Zhang Liang

School of Medicine and Health Management, Tongji Medical College

Huazhong University of Science and Technology

13 Hang Kong Road, Wuhan 430030, Hubei, China

Tel: 86-278-361-0982Ｅ-mail: zhangliang@mails.tjmu.edu.cn

Received: March 15, 2011 Accepted: March 28, 2011 doi:10.5539/gjhs.v3n2p90

\begin{abstract}
The National Health Insurance Scheme (NHIS) in Ghana was established by the National Health Insurance Act, 2003 (Act 650) and National Health Insurance Regulations, 2004 (L.I. 1809) with the view to improving financial access of Ghanaians, especially the poor and the vulnerable, to quality basic health care services and to limit out-of-pocket payments at the point of service delivery. This study is to assess the effect of the Scheme on access to and utilization of healthcare services in the Akatsi District of the Volta region of Ghana. Both qualitative and quantitative data was collected through face-to-face interview with 320 individuals and three service providers using structured questionnaires. The result show that age, level of education and occupation are major determinants of membership of the scheme. The scheme has a positive effect on health seeking behaviour and utilization of health care services by removing significant financial barriers to access. Lack of health insurance serves as a significant barrier to access to modern health care services. Increasing coverage and membership coupled with improvement in geographical access will promote better and overall health outcomes for the people of Ghana.
\end{abstract}

Keywords: National Health Insurance Scheme, Healthcare utilization, Ghana, Akatsi

\section{Introduction}

Many low-and middle-income countries rely heavily on patients' out-of-pocket health payments to finance their health care systems (Xu et al. 2007). According to the World Health Organisation (WHO), empirical evidence indicates that out-of-pocket health payment is the least efficient and most inequitable means of financing health care and prevents people from seeking medical care and may exacerbate poverty (WHO, 2000; Xu et al. 2003; Hjortsberg, 2003).There is a growing movement, globally and in the Africa region, to reduce financial barriers to quality health care generally, but with particular emphasis on high priority services and vulnerable groups (Witter and Garshong, 2009).

Health insurance schemes are increasingly recognized as a tool to finance health care provision in developing countries and has the potential to increase utilization and better protect people against (catastrophic) health expenses and address issues of equity (WHO, 2000). Health financing systems through general taxation or through the development of social health insurance are generally recognized to be powerful methods to achieve universal coverage with adequate financial protection for all against healthcare costs (Weber et al. 2000 cited in Doetinchem et al. 2006; Carrin et al. 2005). Many African countries including Ghana, Rwanda, Tanzania, Kenya and Nigeria are experimenting with a variety of comprehensive, social health insurance schemes that combine both private and public-funding arrangements (Carrin et al. 2008; Witter and Garshong, 2009; Mensah et al. 2010). 
Ghana has prioritized universal coverage, defined as 'access to adequate healthcare for all at affordable price' (WHO, 2005), of health care and has therefore put in place policies and programmes to meet this goal (Osei-Akoto, 2003). A number of health financing reforms have been implemented aimed at increasing overall resources to the health sector and ensuring equitable allocation (Atim et al. 2001),the recent of which is the National Health Insurance Scheme to enhance social health protection. Prior to the establishment of the NHIS in 2003, Ghana has implemented most of the known healthcare financing mechanisms including general tax and donor funding, out-of-pocket payments, community based health insurance schemes. However, these approaches have not been successful in improving access to quality healthcare and reducing out-of-pocket expenditures. For instance, the implementation of the user fee policy (Cash and Carry) in the public sector in 1985 resulted in inequities in financial access and utilization of basic and essential health services between different socio-economic groups and between poor rural and richer urban dwellers (Waddington and Enyimayew 1990; Asenso-Okyere et al. 1998; Nyonator and Kutzin 1999; Agyepong, 1999). Many low-income households regularly postponed medical treatment, resorted to self treatment, or used alternatives provided by unregulated healers, spiritualist, and itinerant drug vendors, often with disastrous results (Oppong, 2001 cited in Mensah et al. 2010).

To cushion the burden of out-of-pocket payment for health care, the government introduced an exemptions policy targeted at children under the age of 5 , prenatal care for pregnant women, the indigent and paupers, the elderly, and for some disease-specific services (Government of Ghana/SAPRI 2001; Sulzbach et al. 2005; Singleton, 2006). Despite having a relatively comprehensive policy, there was considerable evidence that the exemption policy was poorly funded and implemented as many of those who should have been exempted did not receive them (Nyonator et al. 1997). Nyonator and Kutzin (1999) further indicated that, in the Volta region of Ghana, $84 \%$ of patients who were eligible for exemptions did not receive them. The population, therefore, had reduced access to hospital services and, consequently had a negative impact on the financial performance of health facilities (Atim and Sock, 2000).

These difficulties in affording cost of health care and loss of revenue for most health facilities prompted some, mainly mission hospitals, to introduce insurance schemes managed jointly by the facility and the community as a strategy to avoid the problems associated with paying for services at the point of care. By 2003, there were 168 smaller Mutual Health Organizations covering only about 1\% of the population leaving many Ghanaians vulnerable in the event of a catastrophic illness (Atim et al. 2001; Sulzbach et al. 2005).

To remove the financial barriers to access to healthcare services and to ensure equitable access to quality services especially by the poor and vulnerable, the Government of Ghana initiated and passed the National Health Insurance Law, 2003 (Act 650) and the National Health Insurance Regulations, 2004 (L.I. 1809) aimed at abolishing the 'Cash and Carry' system and limiting out-of-pocket payments at the point of service delivery (Government of Ghana, 2004; Agyepong and Adjei, 2008). The policy is also key to Ghana's attainment of the gender and health related Millennium Development Goals (MDGs).By the end of 2009, about 62\% of the population was registered with the scheme with $50 \%$ fully covered with valid identity cards. The scheme being a social health protection intervention and linked to the country's poverty reduction strategy has about $65 \%$ of its membership not paying annual premium. There have been appreciable increases in utilization of healthcare services and reduction in out-of-pocket payments at the point of service. Challenges of organizational arrangement, cost escalation as a result of multiple attendances, increasing high cost of drugs and increase in the number of drugs per prescription have also emerged. Major legal reforms and cost containment initiatives aimed at scaling up the scheme and improving general efficiency are currently underway to resolve these teething problems.

\section{Ghana's National Health Insurance Scheme}

Ghana's National Health Insurance Scheme (NHIS) is a fusion of the traditional Social Health Insurance and Mutual Health Insurance and administered peripherally through 145 district-wide mutual health insurance schemes with a central system at the national level to collect formal sector contributions. The scheme is designed to promote social health protection through risk equalization, cross subsidization, solidarity, equity and quality care. The Health Insurance law (Acts 650) allows for the establishment and operation of three types of health insurance schemes in Ghana namely: District Mutual Health Insurance Schemes (DMHIS), Private Commercial Health Insurance Schemes (PCHIS) and Private Mutual Health Insurance Schemes (PMHIS). However, it is only the DHMIS that shall be provided with subsidy from the National Health Insurance Fund (Government of Ghana, 2003).

\subsection{Funding}

The scheme is financed by a National Health Insurance Levy (NHIL) of 2.5\% tax on selected goods and services, 
a 2.5\% Social Security and National Insurance Trust (SSNIT) deductions from the formal sector, premiums from the informal sector and government budget allocations. The informal sector annual premium was set by national regulation between GH\$7.20-GH\$48.0 (approximately US\$5.0- US\$34.0) per person based on assessed income and ability to pay. No coinsurance, copayment, or deductible is required at the point of service

There exist a National Health Insurance Fund (NHIF), financed from the NHIL, SSNIT deduction from the formal sector employees, funds allocated to the scheme by Parliament, returns on investments made by the National Health Insurance Council (NHIC) and others including grants, donations, gifts made to the fund. The NHIF provides funds for reinsurance to the DMHIS, subsidy or outright pre-payment for the core poor and vulnerable who do not have the ability to pay and to support programs that improve access to health services. The NHIL accounted for about 61.5\% and 61.0\% of total income of the NHIS in 2008 and 2009 respectively. Formal sector contributions made up $16.9 \%$ and $15.6 \%$ while the informal sector premium constituted only $5.0 \%$ and $3.8 \%$ respectively (NHIA, 2010).

\subsection{Exemption}

Children under 18 years, adults 70 years and above, formal sector employees contributing to the Social Security and National Insurance Trust (SSNIT), and indigents are exempted from paying annual premiums. In July 2008, the Government of Ghana announced a free maternal care policy exempting all pregnant women from paying premium and processing fees. The package was to improve access to skilled attendance at delivery to help reduce maternal and child mortality rates and to improve attainment of MDGs 4 and 5. Mothers have access to the full package of antenatal, deliveries and postnatal care at accredited health facilities free of charge (NHIA, 2008; $\mathrm{MOH}, 2009$ ).

As of 2009, the exempt group constituted $70.6 \%$ of the total registrants, comprising of: children under 18 years (49.44\%), aged above 70 years (6.67\%), SSNIT contributors (6.10\%), pregnant women (5.54\%), indigents (2.32\%) and SSNIT pensioners (0.53\%).Total non-paying member accounted for about 65\% (NHIA, 2010).

\subsection{Benefit package}

The minimum benefits package under the NHIS includes general out-patient and in-patient care, oral health, eye care, comprehensive delivery care, diagnostic tests, generic medicines and emergency care. In all over 95\% of the most common disease conditions reported in healthcare facilities in Ghana are covered under the scheme. Highly specialized care such as dialysis for chronic renal failure, organ transplants and services provided under government vertical programs (example: Antiretroviral for the treatment of HIV/AIDS, immunization and family planning), and drugs not listed in the NHIS drug list are not covered.

In order to access healthcare under the NHIS, the National Health Insurance Regulations, L.I. 1809, requires a beneficiary to first report to a primary care facility, and subsequently to a second and third levels of care by way of referral. However poor gate-keeping in the health delivery system in general has led to clients having preferences for higher level facilities which results in higher cost and re-imbursement per episode (Ghana Health Service, 2007)

\subsection{Accreditation of providers and Provider Payment Mechanisms}

In order to provide the basic package of services, the NHIS covers both public and private health care providers at all levels of the health system, subject to their accreditation by the NHIA. At present all public and Christian Health Association of Ghana (CHAG) facilities (about 4000) have been given a provisional accreditation and 1551 private providers including (hospitals and clinics, maternity homes, pharmacies, licensed chemical shops and diagnostic facilities) have been accredited to provide service and to make the service more easily accessible to beneficiaries (NHIA, 2009). Claims are made by service providers and then submitted to the district schemes for payment using the Ghana-Diagnosis Related Group (G-DRG) rates for services and Fee-For-Service (FFS) for medicines. Discussions are ongoing to design, pilot and evaluate a per capita (capitation) provider payment system for primary care under the National Health Insurance Scheme aimed at improving; cost containment, control cost escalation by sharing risk between schemes, providers and subscribers, and improving efficiency through more rational use of health resources (NHIA, 2010).

\section{Method}

The purpose of this study is to assess the effect of the National Health Insurance Scheme on access to and utilization of healthcare services in the Akatsi District of the Volta Region of Ghana and was guided by the following key issues: socio-demographic factors that influence membership; the reasons for joining and barriers to joining the scheme, effect of the scheme on health seeking behaviour and utilization of healthcare service and general views and perceptions about the scheme. 


\subsection{Study design and data collection}

A descriptive and cross-sectional design with both qualitative and quantitative approach was used for this study. Primary data was collected by face-to-face interview using structured and pretested questionnaire. The sample was chosen to include respondents randomly selected across the district and made up of both urban and rural dwellers, the insured and non-insured and subjects 18 years and above. Total number of respondents included was 320.The individual's questionnaire was designed to capture information on socio-demographic characteristics, knowledge and membership of the scheme, health seeking behaviour of both the insured and non-insured, utilization of healthcare services, exemptions, maternal and child health services and general performance of the scheme. In addition to the primary data collected, key persons including three accredited healthcare providers and scheme managers were interviewed to obtain complementary information about the scheme and healthcare delivery. Annual health reports of the district were accessed and analyzed for trends in health services utilization.

The study design and selection of the variables for the study was informed and guided by previous studies on the subject (Jutting and Tine, 2000; Atim and Sock, 2000; Sulzbach et al. 2005; Chankova et al. 2008; NDPC, 2009, Chankova et al, 2009; Mensah et al., 2010). Socio-demographic characteristics of respondents were examined by sex, age, educational status, occupation, marital status and residence. The effect of these characteristics on membership of the scheme was evaluated. Reasons for joining the scheme and barriers to joining were analysed. Health insurance status, health seeking behaviour and healthcare utilization by both the insured and the non-insured were also analysed. Data was collected between April-June 2010.

\subsubsection{Data analysis}

The data was processed and analyzed with Statistical Package for Social Scientist (PASW Statistics 18) and Microsoft Office Excel. Analyses included frequencies, percentage distributions and calculation of mean and standard deviation. Chi-square test of independence was applied to identify the relationship between the basic socio-demographic characteristics and membership of the scheme. A T-test for difference in means was performed to compare the health seeking behaviour and utilization for the insured and the non-insured groups.

\subsubsection{Study context}

The Akatsi District is one of the eighteen (18) administrative districts in the Volta Region of Ghana. The District is located in the south-eastern part of the Volta Region with a total land area of 906445 square kilometres. It is bordered to the south by Keta Municipal, to the east by Ketu District, to the west by both North and South Tongu Districts and to the north by Adaklu-Anyigbey District and the Republic of Togo. It has Akatsi as its District capital. The District is predominantly rural and largely agrarian. It is divided into five sub-districts of Akatsi, Wute, Avenopedo, Gefia and Ave-Dakpa.

The vegetation is low lying forest in the Ave area, shrub land and low savannah in the rest of the district. It has two rainy seasons that is major season in March to June and the minor season begins in September and ends in November. The 2009 population estimates of the district stood at 110 731, made up of 47\% males and 53\% females, (based on projection from the 2000 population census) with an annual growth rate of $1.9 \%$. About $96.3 \%$ of the total population is resident. $79 \%$ of the population lives in the rural areas whiles $21 \%$ live in the urban area. The ethnic composition is made up of the Avenors, Aves and Anlos (Akatsi District Assembly, 2009)

The predominant economic activity of the people is farming which is subsistence, seasonal and dependent on rainfall and trading. It is estimated that agriculture accounts for about $75.5 \%$ of the labour force followed by Trade (18.3\%), Service (3.5\%) and light industry (2.7\%).Infrastructure and social services in the district are inadequate and the conditions of roads, especially feeder roads, are poor and largely unmotorable during the rainy season.

\subsubsection{Healthcare provision}

For the purpose of effective health management and service delivery, the district is demarcated into five sub-districts namely Akatsi, Avenorpeme, Ave-Dakpa, Wute and Gefia. There are 21 health facilities in the district. Out of this number, 17 are Government owned: 1 District Hospital, 5 Health centres and 11 CHPS Zones, while the remaining four are privately owned. There are no mission health facilities in the District but they do exist in the adjoining districts which are readily patronized by the people of the Akatsi Districts.

The Akatsi District Hospital provides out-patient and in-patient care as well as laboratory services. The health centers provide curative, preventive and reproductive and child health (RCH) services. Also, the Community Health Officers (CHOs) in the CHPS zones provide both curative and preventive services.

The privately owned facilities are two clinics manned by doctors, one maternity home and a clinic manned by a 
Medical Assistant. The clinics provide both in-patient and out-patient care. All the privately owned facilities are located in the District capital, Akatsi.The Doctor to population ratio stands at 1: 36,910.

Outside the modern health facilities, are some traditional birth attendants (TBAs) and traditional healers, bonesetters and spiritualists, itinerant drug sellers, registered chemical sellers who constitute alternative sources of health care in the district (Akatsi District Health Report, 2008;2009).

\subsubsection{Health profile of the Akatsi District}

The pattern of diseases continues to be dominated by communicable and preventable diseases; under-nutrition and poor reproductive health (Ministry of Health, 2008; Akatsi District Health report, 2009). Malaria continues to be the disease most commonly reported accounting for more than 55\% of all OPD attendance since 2007. It is the leading cause of mortality in children under five years and a significant cause of adult morbidity. Hypertension, a non-communicable disease, consistently remained the third cause of outpatient morbidity constituting more than five percent of all outpatient reported cases in 2007, 2008 and 2009. According to Christian Health Association of Ghana (CHAG), hypertension is becoming more and more important in rural populations in Ghana (CHAG, 2008).

There has been significant improvement in the use of health services in both the public and private sector in the District, largely attributed to removal of financial barriers to access to health through the National Health Insurance Scheme and the presence of a medical doctor at the District Hospital; however there still exist challenges in geographical, cultural and financial access to healthcare particularly for rural dwellers. The overall trend in OPD attendance increased from 21443 in 2006 to 72185 in 2009. The proportions of the insured using outpatient and inpatient care have increased from $52.8 \%$ and $24.1 \%$ in 2007 to $77.6 \%$ and $65.6 \%$ in 2009 respectively. This suggests that between $22.4 \%$ and $34.4 \%$ of residents who use health facilities in the district still access health care and making payments at the point of service use. The use of antenatal care services stood at $78.0 \%$ in 2009. Supervised delivery by a trained health worker is low increasing from $22.0 \%$ in 2008 to $31.2 \%$ in 2009. Postnatal care coverage also improved marginally from $68.0 \%$ in 2008 to $69.2 \%$ in 2009 . Use of family planning services was low at $15.4 \%$ in 2009.

\subsubsection{Overview of the Akatsi District Mutual Health Insurance Scheme}

The Akatsi District Health Insurance Scheme (ADMHIS) is one of the nationally mandated schemes established by law in October 2004 to equitably increase financial access to healthcare in the District. The scheme covers persons in both the formal and informal sectors of the economy in the District.

The membership of the scheme is open to all residents in the District. Registration for membership and renewal is open throughout the year and is mainly done at the district office located at the capital and minimally through community premium collectors. Patronage of the schemes has been increasing over the years. Total membership of the scheme as of 2009 was 70350 representing about $63.5 \%$ of the district population. $34.3 \%$ of members are in the informal sector while $2.2 \%$ were SSNIT contributors. Total non-premium paying members constitute $63.5 \%$ (ADMHIS, 2010).

The premium for the informal sector, currently, is set at a flat rate of GH\$10.0 per annum in addition to a registration fee of GH\$2.0 for the informal sector. The exempt category (SSNIT contributors, the aged above 70 years) pays a registration fee of GH\$2.0. Children below 18 years pay GH\$1.0 registration fee. There was no evidence of payment of premium based on income levels as enshrined in the law. This has been attributed to difficulty in assessing the income levels of the largely informal sector in the district.

The scheme has accredited 14 healthcare facilities in and outside the District, to provide services for its members. Only one of the eleven (11) CHPS Compounds is accredited in the District. One chemical shop is also accredited. Claims are made by service providers and then submitted to the district scheme for payment using G-DRG rates for services and Fee-For-Service (FFS) for medicines.

The ADMHIS is governed by a board whose responsibilities among others include negotiating service contract with service providers and identifying the core poor for free access. The staff in-charge of the day-to-day administration of the district schemes includes among others: the Scheme Manager, Accountant, Management Information System Manager, Claims Manager and Publicity and Marketing Manager.

\section{Results}

\subsection{Background characteristics of respondents}

Table 1 presents the basic descriptive statistics of the background characteristics of the respondents. Out of the 320 respondents interviewed, $45.9 \%$ were male and $54.1 \%$ female. The mean age of the direct respondents was 33.3 years with standard deviation of 11.69 . The minimum and maximum ages were 18 and 75 years respectively. 
About 63\% of respondents were aged between 18 and 35 years old .The educational attainments of respondents revealed that $6.9 \%$ had no formal education, $36.9 \%$ had basic education, $21.3 \%$ secondary and $35.0 \%$ above secondary. More males (34.3\%) attained higher education of secondary and above, than females (21.9\%).The informal sector constituted $46.9 \%$, majority of whom are employed in agriculture (21.9\%) supporting that fact that the study area is largely rural and agrarian. The formal sector constitutes $34.1 \%$. The unemployed and students made up $4.1 \%$ and $15.0 \%$ respectively. The result further indicated that $60.7 \%$ of respondents are married, $34.7 \%$ single while $4.6 \%$ are separated, divorced or widowed. Rural respondents constituted $71.9 \%$, while $28.1 \%$ were drawn from the urban area

\subsection{Knowledge and membership of the scheme}

Basic knowledge on the scheme is high with $99.1 \%$ of respondents hearing of the scheme largely through the electronic media; radio and television (47.9\%).Other sources were through: health staffs (21.2\%), community leaders $(10.2 \%)$, managers of the scheme $(9.3 \%)$, a relative $(7.4 \%)$ and a member of the scheme $(4.0 \%)$. Of the 320 respondents, $76.9 \%$ were registered with the scheme while $23.1 \%$ were not members. The informal sector constituted $35.3 \%$ of membership. A greater proportion of members (61.8\%) are willing to remain as members of the scheme to enjoy its benefits even if the current premium levels are raised. For those who may consider opting out in the event of increase in premium levels cited reasons of erosion of SSNIT contribution and difficulty in paying for households and dependant.

The result demonstrates that age $(\mathrm{P}=0.002)$, level of education $(\mathrm{P}=0.030)$ and occupation $(\mathrm{P}=0.039)$ were significant determinant of membership of the scheme. With regards to age, respondents with ages between 18-29years are more likely to join the scheme. This may also be a reflection of the youthful nature of the population. With level of education, there is a significant difference between the insured and the non-insured, with about $46 \%$ of the insured having secondary education and above as compared to $10.6 \%$ of the non-insured. Greater percentages of the insured are employed in all sectors than the non-insured. Higher proportions of those employed in the informal sector (46.9\%) tend to be enrolled in scheme. A higher proportion of female (42.8\%), the married (46.9\%) and rural dwellers (54.4\%) tend to be enrolled in the scheme. However these are not statistically significant.

\subsection{Reasons for joining the scheme and barriers to enrolment}

The major reason stated by respondents for joining the scheme was that it provides free access to medical care (50.9\%). Others reported were cost effectiveness (25.3\%), security and peace of mind in times of ill-health (19.6\%). 4.3\% of members reported facing health problem for joining the scheme. Insured respondents (53.5\%) reported having faced difficulties when enrolling in the scheme. The responses suggest that the difficulties were largely institutional and operational and include delays in the issuance of identity cards (41.7\%) and in the registration process (26.8\%), registration centres far away (11.9\%) and education on the scheme not enough (8.3\%).

For the non-insured, affordability of premium and contributions was mentioned as the major barrier to enrolment (41.9\%).The proportion was higher among the rural dwellers (33.8\%) than urban dwellers (8.1\%). Other reasons mentioned included: NHIS does not cover all my health needs (18.9\%), do not need health insurance or not interested (17.6\%). Interestingly, $10.8 \%$ of the rural respondents do not trust the organizers of the scheme. In order to be enrolled in the scheme, reduction in the premium $(41.9 \%)$, openness of organizers $(32.9 \%)$ and registration at the community level (15.1\%) were suggested.

\subsection{Health seeking behaviour of the insured and non-insured}

Table 2 shows the health seeking behaviour of both the insured and the non-insured in relation to formal care-seeking practices and use of maternal health services. Higher proportion of the insured (70.8\%) than the non-insured (6.0\%) reported seeking formal care during ill-health. The insured received services ranging from consultation and treatment (54.7\%), medicines/drugs (18.6\%), laboratory services (9.8\%), delivery (8.8\%) and hospitalization (8.1\%). Government health facilities are the first point of call for most respondents especially the Government Hospital at the District capital for both the urban and rural dwellers. This is followed by private health facilities all located at the District capital (22.0\%).The proportion that uses health centres located close to the communities accounts for $6.6 \%$. None reported using the CHPS compounds. Reasons for choice of a facility were: competence and friendly staffs (30.1\%), reputation of provider (19.5\%), availability of medicines (17.2\%), prompt attention (16.3\%). About $17 \%$ of the responses were related to cost and proximity to a health facility respectively. Higher proportions (63\%) of the female insured respondents who gave birth during the last 12 month preceding the survey as compare with the non-insured (4.7\%) gave birth in a health facility and were assisted by a trained health personnel (75.0\%).Use of postnatal care services is also higher among the insured (67.2\%) than the non-insured (7.8\%). 
Lack of insurance (42.3\%) is the single most important reason for not seeking formal care among the non-insured. A higher proportion of the non-insured who did not seek care (48.1\%) either delays or postpones treatment. The result revealed that health insurance is a key determinant in seeking healthcare and using modern health faculties. Care-seeking, choice of health facility, place of last birth, professional attendance at delivery and use of postnatal care services are all statistically significant.

\subsection{Views and perceptions on the scheme and service delivery}

Majority of the insured (67\%) indicated receiving good quality of service with $33.0 \%$ stating otherwise. Unavailability of essential drugs (39.0\%) and long waiting time (31.4\%) respectively were the major reasons stated for the low quality of service received. From the perspective of the non-insured, quality of healthcare delivery in the district is rated as low. Waiting time, cost of treatment, quality of drugs, availability of drugs at the facility were rated as 'worse than before' while privacy during examination and treatment and availability of laboratory services at the facility were rated as 'same as before'. Findings of the survey indicate that respondents are generally satisfied with the performance of the scheme in the district; with $71.6 \%$ of the insured indicating they are either satisfied or very satisfied. 19.3\% reported either being dissatisfied or very dissatisfied with performance of the scheme.

\section{Discussion}

Majority of the respondents (46.9\%) are employed in the informal sector, which is largely consistent with the Ghana Living Standard Survey Round 5 of 2008,which suggests that majority of Ghanaians are engaged in the informal sector of the economy. The informal sector accounted for $35.3 \%$ of membership. This is generally consistent with the data from the ADMHIS and NHIA which indicated that nearly $30 \%$ of those registered under the scheme are in the informal sector. Given the fact that close to $50 \%$ of respondents and Ghanaians are engaged in the informal sector, greater effort should be made to get them enrolled into the scheme in order to improve the financial base of the scheme and to improve access to quality health care for the largely informal sector. None of the respondents reported being an indigent. This may be attributed to the strict nature of the means test and the difficulty in identifying the indigents. Currently, only about $0.3 \%$ of the district population is registered as indigents.

Information on the scheme is high partly attributed to the commitment of all stakeholders and vigorous marketing and mobilization strategies by both the National Health Insurance Authority and the management of the District scheme. On the determinants of membership age, sex, level of education, marital status, and community description have been analysed regarding their influence on membership. The findings demonstrate that age, educational level and occupation positively affect membership of the scheme. Level of education and literacy has been found by other studies to be an important determinant in the demand for health insurance and healthcare services. Respondents with secondary education and above are more likely to be enrolled in the scheme. This finding is consistent with the results obtained by Jutting (2000); Kirigia (2005); National Planning Development Commission of Ghana (2009), Mensah et al. (2010). Sex, marital status and description of community do not have statistically significant influence on membership of the scheme. Even though a higher proportion of respondents are females do not seem to be a major determinant in enrolling in the scheme, suggesting that a gender bias participation is not observed in the scheme.

Majority of the respondents recognized the scheme as offering them financial protection against catastrophic health payments at the time of ill-health rather than as a response to facing a health problem. The economically active groups of the population are relatively more covered by the scheme. These suggest that, membership of the scheme did not seem to be driven by adverse selection.

The study indicates that affordability of premiums is still an obstacle in joining the scheme. This is in line with findings of Criel and Waelkens, 2003; Carrin et al. 2005; Chankova et al. 2008; Chankova et al. 2009 and Mensah et al. 2010. This calls for strengthening of the exemption policy especially for the poor and vulnerable to ensure equity in access to health services which is one of the mandates of the NHIS (NDPC, 2009). Apart from cost, other obstacles affecting are institutional and operational challenges including: delays in the registration process and in issuance of identity cards, registration centre far away and lack of trust in the organizers of the scheme. According to Carrin et al. (2005), trust in the integrity and competence of managers of schemes may have an effect on enrolment. These bottlenecks, when addressed can help improve the coverage and membership of the scheme.

The scheme in the district adheres to the minimum benefit package in the insurance law with respondents benefiting from wide range of services. The result revealed a weak gate-keeping system in the health delivery system, where most people do not make use of the health centres and CHPS compounds located in their communities. Various factors including lack of trust in these facilities, lack of skilled personnel, inadequate basic 
equipments and supplies needed to provide quality curative health care at the lower level health facilities. Available data from the ADMHIS revealed that only one CHPS compound out of the eleven in the district is accredited under the health insurance scheme. This arrangement defeats the gate-keeper system and thus also increase cost of service to the rural dwellers in terms of transport cost to the district capital. The choice of a health facility is driven by quality considerations rather than cost and distance from the health facility (Criel and Waelkens, 2003). Improvement in the quality of service delivered by the health centres and CHPS zones will bring health services closer to the door steps of the rural dwellers

The scheme has positively affected health seeking behaviour and utilization of healthcare services and has the potential of reducing out-of-pocket payments at the point of service use. For instance, access to NHIS has a significant influence on the use of maternal and child care services in the district and has the potential to improve the attainment of MDGs 4 and 5 as insured women are more likely to deliver at a health facility and supervised by a trained health personnel and pay less than the non-insured. This is consistent with previous literature on health insurance schemes (Mensah et al. 2010; Shimeles, 2010; Saksena et al. 2010; Nguyen et al. 2010; Chankova et al. 2009; Xu et al. 2009; Chankova et al. 2008); and data obtained from the annual health insurance and health reports (National Health Insurance Authority, 2010; Christian Health Association of Ghana, 2008; Ghana Health Service, 2009).From the result, it is apparent that lack of health insurance serves as a significant barrier to access to modern health care services especially among the rural dwellers. A higher proportion of the non-insured (47.1\%) are more likely to delay seeking healthcare, postpone and engage in self treatment which could result in complications and poor health outcomes.

Anecdotal evidence suggests that there exists over-utilization and health shopping among health facilities by the insured, an evidence of moral hazard and a negative effect on the quality of healthcare being delivered as a result of the increasing utilization. The perceived low quality of service received from healthcare providers were attributed to unavailability of drugs and long waiting times. The seemingly unavailability of drugs was in part attributed to delays in submission of claims by health facilities and reimbursement by the scheme, which put financial burden on the facilities considering the fact that most of them now earn more than $80 \%$ of their revenue from insurance (Field survey, 2010; GHS, 2009).The delays experienced during care where attributed to the manual filling of forms for the insured, high attendance and inadequate professional staff at the health facilities (Field survey, 2010). This real or perceived perception of low quality of health care in the District could serve as a barrier to enrolment and renewal of membership with the scheme as was suggested by Criel and Waelkens, 2003 and Carrin et al. 2005.

Generally, respondents and Ghanaians are satisfied with the performance of the National Health Insurance Scheme (NDPC, 2009) and as suggested by Zhu et al. (2008), direct experience with health insurance reinforced a better understanding and opinion of the insurance system. Other findings revealed that, there exist a strong political will and commitment on the part of government and stakeholders both at the national and local level to increase access and utilization of healthcare services in order to improve universal coverage. Community acceptance of the scheme as a social protection intervention is high (NDPC, 2009, Field survey, 2010).

\section{Conclusion and recommendation}

The study concludes that, the NHIS has improved access to healthcare services to different category of people in the Akatsi District by removing significant financial barriers to access. The findings suggest that the National Health Insurance Scheme positively affected health seeking behaviour, access to modern health care services and likelihood of delivery at a health facility and being assisted by trained health personnel. NHIS also had effect on postnatal care but found no evidence of it on usage of antenatal care. Increasing access and coverage to the National Health Insurance Scheme and removal of geographical barriers to health will promote better health and overall health outcomes for the people of Ghana. Greater awareness on the benefits of the scheme especially among the largely informal sector and purposeful targeting of the core poor will help improve on the coverage and membership of the scheme. More client-oriented community education on the benefits of the scheme and membership registration at community durbars, major market days should be undertaken to improve access and coverage.

The study also recommends registering the informal sector through existing groups and associations in which premium could be paid on instalment basis through them. There is the need to take a critical look at expanding geographical access to quality healthcare, especially primary health care in the rural areas in order to achieve universal coverage. There is also the need to establish permanent and functional structures of arbitration to constantly engage the scheme management, healthcare providers and subscribers in order to minimize the mistrust and improve uptake and service delivery. 


\section{References}

Agyepong, I. A. (1999). Reforming health service delivery at district level in Ghana: the perspective of a district medical officer. Health Policy and Planning, 14 (1), 59-69.

Agyepong, I. A. \& Adjei, S. (2008). Public social policy development and implementation: a case study of the Ghana National Health Insurance scheme. Health Policy and Planning, 23 (2), 150-160. http://dx.doi.org/10.1093/heapol/czn002

Akatsi District Health Directorate. (2008). Annual Health Report.

Akatsi District Health Directorate. (2009). Annual Health Report.

Asenso-Okyere, W. K., Anum, A., Osei-Akoto, I., \& Adukonu, A. (1998). Cost recovery in Ghana: are there any changes in health seeking behaviour? Health Policy and Planning, 13 (2), 181-188.

Atim, C. \& Sock, M. (2000). An External Evaluation of the Nkoranza Community Financing Health Insurance Scheme, Bethesda: Partnerships for Health Reform.

Atim, C., Grey, S., Apoya P, et al. (2001). A survey of health financing schemes in Ghana. Bethesda, MD: Partners for Health Reformplus, Abt Associates Inc.

Carrin, G., et al. (2005). Community-based health insurance in developing countries: a study of its contribution to the performance of health financing systems. Tropical Medicine \& International Health, 10 (8), 799-811.

Carrin, G., Doetinchem, O., Kirigia, J., Mathauer, I., \& Musango, L. (2008). Social health insurance: how feasible is its expansion in the African region? Development Issues, 10, 2.

Chankova, S., Sulzbach, S., \& Diop, F. (2008). Impact of mutual health organizations: evidence from West Africa. Health Policy and Planning. 23, 264-276. http://dx.doi.org/10.1093/heapol/czn011

Chankova, S., Sulzbach, S., et al. (2009). An evaluation of the effects of the National Health Insurance Scheme in Ghana. Bethesda, MD: Health Systems 20/20 project, Abt Associates Inc.

Christian Health Association of Ghana. (CHAG). (2008). Annual Christian Health Association of Ghana Report.

Criel, B. \& Waelkens, M. P. (2003). Declining subscriptions to the Maliando Mutual Health Organisation in Guinea-Conakry (West Africa): what is going wrong? Social Science and Medicine, 57, 1205-1219. http://dx.doi.org/10.1016/S0277-9536(02)00495-1

Doetinchem O., Schramm B., \& Schmidt J. O. (2006). The benefits and challenges of social health insurance for developing and transitional countries. In: U. Laaser, \& R. Radermacher (Eds.), Financing health care - A dialogue between South Eastern Europe and Germany. Series International Public Health, Vol. 18.

Ghana Health Service. (2007). Annual Report.

Ghana Health Service. (2009).The Health Sector in Ghana. Facts and Figures, 2009.

Ghana Statistical Service and Ghana Health Service. (2009). Ghana Demographic and Health Survey, 2008. Accra, Ghana.

Ghana Statistical Service. (2008). Ghana Living Standards Survey Report of the Fifth Round (GLSS 5).

Government of Ghana / SAPRI. (2001). Impact of Structural Adjustment Programme on availability and access to healthcare. Draft, April 2001.

Government of Ghana. (2003). National Health Insurance Act, 2003 (Act 650). Accra.

Government of Ghana. (2004). National Health Insurance Regulations, 2004 (L.I. 1809). Accra.

Hjortsberg, C. (2003). Why do the sick not utilize health care? The case of Zambia. Health Economic, 12, 70-75. http://dx.doi.org/10.1002/hec.839

Jütting, J. \& Tine, J. (2000). Micro Insurance Schemes and Health Care Provision in Developing Countries: An Empirical Analysis of the Impact of Mutual Health Insurance Schemes in Rural Senegal. Center for Development Research (ZEF), Bonn.

Jutting, J. P. (2003). Do community-based Health Insurance Schemes Improve Poor People's Access to Health Care? Evidence from Rural Senegal. World Development, 32 (2), 273-288. http://dx.doi.org/10.1016/j.worlddev.2003.10.001

Mensah, J., Oppong, J. R., \& Schmidt, C. M. (2010). Ghana’s National Health Insurance Scheme in the Context of the Health MDGs: An Empirical Evaluation Using Propensity Score Matching. Health Economics, 19, 95-106. 
Ministry of Health, Ghana. (2009). Independent Review: Health Sector Programme of Work 2008. Draft, April 2009, Accra.

National Development Planning Commission. (2009). 2008 Citizens' Assessment of the National Health Insurance Scheme of Ghana, Towards a Sustainable Health Care Financing Arrangement that Protects the Poor. NDPC. Accra.

National Health Insurance Authority. (NHIA). (2009). Status of NHIS and New Strategic Direction. NHIA Presentation at Health summit, November 2009, GIMPA, Accra.

National Health Insurance Authority. (2010). Financial implications to achieving the MDGs: How to Meet the Costs, NHIA Presentation at Health Summit, November, 2010, Accra.

National Health Insurance Authority. (2010). National Health Insurance Scheme, Annual Report 2009. Accra.

National Health Insurance Authority. (NHIA). (2008). Providing Free Maternal and Neonatal Health care through NHIS. NHIA Presentation at Health summit, November 2008. Accra.

Nguyen et al. (2011). The financial protection effect of Ghana National Health Insurance Scheme: evidence from a study in two rural districts. International Journal for Equity in Health, 10, 4. http://dx.doi.org/10.1186/1475-9276-10-4.

Nyonator, F. \& Kutzin J. (1999). Health for some? The effects of user fees in the Volta Region of Ghana. Health Policy and Planning, 14 (4), 329-341.

Osei-Akoto, I. (2003). Demand for voluntary health insurance by the poor in developing countries: Evidence from rural Ghana. Center for Development Research (ZEF). University of Bonn, Germany.

Saksena, P., Antunes, A. F., Xu, K., Musango, L., \& Carrin, G. (2010). Impact of mutual health insurance on access to health care and financial risk protection in Rwanda. Discussion paper, 3/2010.WHO.Geneva.

Shimeles, A. (2010). Community based health insurance schemes in Africa: the case of Rwanda, Development Research Department, African Development Bank.

Singleton, J. L. (2006). Negotiating Change: an Analysis of the Origins of Ghana's National Health Insurance Act. Department of Sociology, Macalester College.

Sulzbach, S., Garshong, B., \& Owusu-Banahene, G. (2005). Effects of the National Health Insurance Act in Ghana: Baseline Report, Bethesda, M. D. Partners for Health Reformplus, Abt Associates Inc.

Waddington, C. \& Enyimayew, K. A. (1990). A price to pay: The impact of user charges in the Volta region of Ghana. The International Journal of Health Planning and Management, 5 (4), 150-160. http://dx.doi.org/10.1002/hpm.4740050405

Witter, S. \& Garshong, B. (2009). Something old or something new? Social health insurance in Ghana. BMC International Health and Human Rights, 9, 20. [Online] Available: http://www.biomedcentral.com/1472-698X/9/20.

World Health Organisation. (2005). World Health Report 2005. World Health Organisation, Geneva,

World Health Organization. (2000). The World Health Report 2000. Health systems: Improving performance. World Health Organization, Geneva.

World Health Organization. (2007). Everybody business: strengthening health systems to improve health outcomes. WHO's framework for action.

Xu, et al. (2009). Health Care Financing in Rural China: New Rural Cooperative Medical Scheme. Technical brief for policy makers, Number 3/2009. World Health Organization, Geneva. [Online] Available: www.who.int/health_financing/documents/cov-pb_e_09_03-china_nrcms

Xu, K., Evans, D., et al. (2003). Households catastrophic health expenditure: a multicounty analysis. Lancet, 362, 111-117.

Xu, K., Evans, D., Carrin, G., Aguilar-Rivera, A. M., Musgrove, P., \& Evans, T. (2007). Protecting households from catastrophic health spending. Health Affairs (Millwood), 26, 972-983. http://dx.doi.org/10.1377/hlthaff.26.4.972

Zhu, J. M., Zhu, Y., \& Liu, R. (2008). Health insurance of rural/ township schoolchildren in Pinggu, Beijing: coverage rate, determinants, disparities, and sustainability. International Journal for Equity in Health, 7, 23. http://dx.doi.org/10.1186/1475-9276-7-23 
Table 1. Effect of socio-demographic characteristics on access to health insurance

\begin{tabular}{|c|c|c|c|c|}
\hline Background Characteristics & Insured(N=247) & Non-Insured $(\mathrm{N}=74)$ & & \\
\hline & $\mathrm{n}(\%)$ & $\mathrm{n}(\%)$ & Total (\%) & P-value \\
\hline Sex & & & & 0.354 \\
\hline Male & $110(34.4)$ & $37(11.6)$ & 45.9 & \\
\hline Female & $137(42.8)$ & $36(11.3)$ & 54.1 & \\
\hline Age group & & & & $\mathbf{0 . 0 0 2}$ \\
\hline $18-24$ & $60(18.8)$ & $16(5.0)$ & 23.8 & \\
\hline $25-29$ & $42(13.1)$ & $27(8.4)$ & 21.6 & \\
\hline $30-34$ & $37(11.6)$ & $7(2.2)$ & 13.8 & \\
\hline $35-39$ & $34(10.6)$ & $10(3.1)$ & 13.8 & \\
\hline $40-44$ & $21(6.6))$ & $9(2.8)$ & 9.4 & \\
\hline $45-49$ & $21(6.6))$ & $2(0.6)$ & 7.2 & \\
\hline$\geq 50$ & $32(10.0)$ & 2(0.6) & 10.6 & \\
\hline \multicolumn{4}{|l|}{$\begin{array}{l}\text { Mean Age: } 33.29 \pm 11.69 \\
\text { age=75years }\end{array}$} & Maximum \\
\hline Ever attended School & & & & 0.288 \\
\hline Yes & 228(71.3) & $70(21.9)$ & 93.2 & \\
\hline No & 19(5.9) & $3(0.9)$ & 6.8 & \\
\hline Level of Education & & & & $\mathbf{0 . 0 3 0}$ \\
\hline None & 19(5.9) & $3(0.9)$ & 6.8 & \\
\hline Elementary/Basic & $82(25.6)$ & $36(11.3)$ & 36.9 & \\
\hline Secondary & 51(15.9) & $17(5.3)$ & 21.3 & \\
\hline Above Secondary & 95(29.7) & $17(5.3)$ & 35.0 & \\
\hline Occupation & & & & 0.039 \\
\hline Government worker & 93(29.1) & $16(5.0)$ & 34.1 & \\
\hline Farmer & $50(15.6)$ & $20(6.3)$ & 21.9 & \\
\hline Trader & $39(12.2)$ & $14(4.4)$ & 16.6 & \\
\hline Tradesman/Artisan & $9(2.8)$ & $8(2.5)$ & 5.3 & \\
\hline Driver & $7(2.2)$ & $3(0.9)$ & 3.1 & \\
\hline Student & $40(12.5)$ & $8(2.5)$ & 15.0 & \\
\hline Unemployed & $9(2.8)$ & $4(1.3)$ & 4.1 & \\
\hline Marital status & & & & 0.640 \\
\hline Single & $83(25.9)$ & $28(8.8)$ & 34.7 & \\
\hline Married & $150(46.9)$ & $44(13.8)$ & 60.7 & \\
\hline Divorced & 10(3.1) & $1(0.3)$ & 3.4 & \\
\hline Separated & $2(0.6)$ & $0(0.0)$ & 0.6 & \\
\hline Widowed & $2(0.6)$ & $0(0.0)$ & 0.6 & \\
\hline Community description & & & & 0.295 \\
\hline Urban & $73(22.8)$ & $17(5.3)$ & 28.1 & \\
\hline Rural & $174(54.4)$ & $57(17.5)$ & 71.9 & \\
\hline
\end{tabular}

Bold indicates that chi-square test is statistically significant at $\mathrm{p}=0.05$ level. Source: Field survey, 2010 
Table 2. Health seeking and utilization of healthcare services

\begin{tabular}{|c|c|c|c|c|}
\hline Variables & Insured & Non-Insured & & \\
\hline & n (\%) & n (\%) & Total (\%) & P-value \\
\hline Seek care the last time & & & & 0.000 \\
\hline Yes & $225(70.8)$ & $19(6.0)$ & 76.7 & \\
\hline No & 2(6.6) & $53(16.7)$ & 23.3 & \\
\hline Where care is normally sought & & & & 0.002 \\
\hline Government Hospital & $144(45.3)$ & $8(2.5)$ & 47.8 & \\
\hline Government Health centre/clinic & $18(5.7)$ & $3(0.9)$ & 6.6 & \\
\hline Private facility & $63(19.8)$ & $7(2.2)$ & 22.0 & \\
\hline Traditional healer & $0(0.0)$ & $1(0.3)$ & 0.3 & \\
\hline Given birth the last 12 month & & & & 0.609 \\
\hline Yes & $52(30.1)$ & $12(6.9)$ & 37.0 & \\
\hline No & $85(49.1)$ & 24(13.9) & 63.0 & \\
\hline Prenatal Care & & & & 0.098 \\
\hline Yes & $50(78.1)$ & $10(15.6)$ & 93.8 & \\
\hline No & $2(3.1)$ & $2(3.1)$ & 6.2 & \\
\hline Place of last birth & & & & 0.001 \\
\hline Government Facility & $35(54.7)$ & 1(1.6) & 56.3 & \\
\hline Private Facility & $5(7.8)$ & $2(3.1)$ & 10.9 & \\
\hline Home & 12(18.8) & $9(14.1)$ & 32.9 & \\
\hline Who assisted birth & & & & 0.002 \\
\hline Trained Health Personnel & 39(60.9) & $3(4.7)$ & 65.6 & \\
\hline Traditional Birth Attendant & $9(14.1)$ & $8(12.5)$ & 26.6 & \\
\hline Self/Family member & $4(6.3)$ & $1(1.6)$ & 7.8 & \\
\hline Postnatal Care & & & & 0.003 \\
\hline Yes & $43(67.2)$ & $5(7.8)$ & 75.0 & \\
\hline No & $9(14.1)$ & $7(10.9)$ & 25.0 & \\
\hline Source of payment for birth & & & & 0.000 \\
\hline Self/Family & $14(22.6)$ & $10(16.1)$ & 38.7 & \\
\hline NHIS & $36(58.1)$ & $2(3.2)$ & 61.3 & \\
\hline
\end{tabular}

Bold indicates that chi-square test is statistically significant at $\mathrm{p}=0.05$ level. Source: Field survey, 2010 